\title{
EL PENSAMIENTO IRRACIONAL ISLÁMICO: EL. SUFISMO DE SOHRAWARDI
}

\author{
Juan Manuel Aragués \\ Universidad de Zaragoza
}

En la presente comunicación se va a realizar un breve recorrido por la obra de Sohrawardi de Alepo, en cuyo discurso las tendencias esotéricas y místicas prenden con profundidad, quizá com reflejo de las tradiciones zoroástricas y herméticas, entre otras, que se desarrollaron en su zona de origen.

Se podría decir que el origen de la filosofía de Sohrawardi se halla en la certeza de la existencia de un Dios único causa de todo lo existente y que se constituye, por lo tanto, en el Ser por excelencia. El resto de lo existente no es sino una manifestación más o menos pura de Dios, por lo quela mayor o menor proximidad a Este impone una jerarquización, ontológicamente cualitativa, del Universo, del resto de los seres que participan en el Ser de Dios. De aquí es de donde parte la teoría de Sohrawardi de la existencia de diferentes mundos, diferentes modos de conocimiento, diferentes tipos de decurso histórico, diferentes formas de ser individual, en relación a la participación del ser de Dios. Cada uno de los grados de la jerarquía es real ontológicamente; sus diferencias estriban en la diferente proximidad al amor de Dios. Así como para Schopenhauer la forma de arte más perfecta es aquélla que menos corrupta se halla por la materialidad, así también, para la metafísica de Sohrawardi, el ser más perfecto es aquél que más absuelto está de la materialidad. Todo es ser, desde el Uno hasta las formas sensibles, pero la perfección se encuentra en el Uno y va remitiendo conforme el ser se reviste de materialidad. De este modo, se construye una metafísica, por utilizar palabras de Dodds ${ }^{1}$, de carácter puritano, por cuanto la perfección espiritual aumenta conforme disminuye el vínculo con lo material.

La realidad se constituye en una dimensionalidad cuadruple, en cuyos extremos se hallan la forma más perfecta del Ser, el Uno, y la más corrupta, el mundo sensible. Por debajo del

1 Dodds, E. R., Los griegos y lo irracional Alianza Universidad, Madrid, 1983, p. 149. 
Uno, según la lectura de Sohrawardi, hay tres universos o tres categorías de universos: el mundo físico sensible, compuesto por nuestro mundo sensible, gobernado por las almas humanas, y por el universo sideral, gobernado por las almas de las esferas; el mundo suprasensible del alma, donde se encuentran las ciudades místicas, Jâbârsâ, Jâbalqâ y Hurqalyâ, las ciudades de Esmeralda, pues representan el color verde; por último, el universo de las inteligencias puras arcangélicas. Estos tres mundos se encuentran por debajo del Uno trascendental e incognoscible. A cada uno de ellos les corresponde un órgano de conocimiento ${ }^{2}$, los sentidos, la imaginación y el intelecto, triada a la que corresponde la triada antropológica cuerpo, alma, espíritu.

Entre los mundos extremos se manifiesta el Mundus Imaginalis, cuya entidad ontológica, aunque imaginal, no tiene nada que envidiar a la de los otros mundos. En dicho mundo comienza a producirse el acercamiento a la divinidad, si tomamos la perspectiva del hombre, o su desvelamiento, si tomamos la suya propia; es un momento en el camino de ascenso del hombre a Dios, $t a$ 'wil , o de descenso de la esencia del Uno hacia el mundo sensible, tanzil . Debido a su identidad ontológica, a su realidad imaginal, posee formas de manifestación propias: no sólo un órgano de conocimiento adecuado a su realidad, como ya hemos mencionado, la imaginación, sino también una Historia imaginal y una Geografía imaginal.

El órgano de conocimiento adecuado para la aprehensión del Mundus Imaginalis es la imaginación que, a un mismo tiempo, en un mismo acto, crea y conoce las sustancias del Mundo Imaginal. Es lo que Mollâ Sadrâ Shîrâzî denomina imaginación creadora ${ }^{3}$. El carácter doble de la imaginación creadora viene definido por la inmaterialidad de las sustancias del Mundo Imaginal, hecho que obliga a la imaginación a dotar de una existencia real, aunque inmaterial, a las sustancias imaginales. Al reconocer su existencia las produce como realmente existentes, las extrae a la realidad, haciendo sensible otro mundo que sin ella quedaría innombrable. Por ello, conciencia y objeto son «ontológicamente inseparables», por cuanto el objeto existe en cuanto es puesto por la conciencia, al tiempo que la forma de ésta depende del carácter del objeto. El proceso de conocimiento se convierte en un proceso de captación de realidad oculta, de manifestación, de Epifanía de unas formas de ser más cercanas al Ser. Todo lo que existe en el mundo sensible tiene su correlato imaginal en este mundo. El binomio materialidad/realidad es superado por una gnoseología esotérica.

Como hemos indicado, el Mundo Imaginal es un lugar de paso en el ascenso ( taw $^{\prime} i l$ ) hacia el Ser o en el descenso (tanzil) de éste hacia el hombre. Esta especificidad de carácter ontológico implica una localización geográfica determinađa, lo que se denomina octavo clima, por oposición a los siete climas que componen nuestro mundo sensible 4 . Es un lugar fuera de lugar, un clima fuera de los climas, fuera de donde (Nâ-Kojâ-Abâd). Es, con respecto al mundo sensible, el mundo de los orígenes y de los regresos: de los orígenes en cuanto que en su parte oriental, en la ciudad de Jâbâlq $\hat{a}$, preexisten los arquetipos (de ahí su nombre en árabe, âlam

2 Corbin, H., Face de Dieu, Face de l'Homme. Hermenéutique et soufisme Flammarion, Paris, 1983, p. 15.

3 Jambet, C., La logique des Orientaux Gallimard, Paris, 1983, pp. 53 y ss.

4 Corbin, H., Op. cit. p. 16. 
al-mithâl, o mundus arquetipus) de las imágenes sensibles; regreso por cuanto en su zona ocidental, en la ciudad de Jabarsa, se hallan todos los espíritus tras su paso por el mundo sensible. ${ }^{5}$ La existencia geográfica del Mundus Imaginalis proporciona el lugar para la manifestación de formas no sensibles, correlato de las que han existido, existen o existirán sobre el mundo sensible, al tiempo que permite un cierto grado de desvelamiento de la profecía, de manifestación del Ser, de lo Oculto. De esta forma, en la jerarquización ontológica de los mundos de Sohrawardi, todo lo que es aparente, al-zahir, en un mundo inferior, tiene su correlato oculto, al-bâtin, en un mundo superior, al tiempo que este bâtin se convertirá, en su desvelamiento, en un zahir para otro bâtin al-bâtin de un mundo todavía superior. ${ }^{6}$ De este modo, el símbolo se constituye en una figura central en la filosofía esotérica de Sohrawardi:

«La transformación oriental del mundo del Alma del neoplatonismo helénico en un mundo de la imaginación es la gran revolución de la espiritualidad islámica (...) El símbolo no es una aproximación inferior a la idea, es el modo del Uno en el Alma. El símbolo es la realidad misma transportada a un grado de ser diferente, es la repetición de la realidad en otro mundo, tan real como esta realidad misma»?

En consonanacia con su entidad geográfica, el Mundo Imaginal también goza de una entidad histórica, posee un modo propio, imaginal, de devenir histórico en relación con su carácter ontológico específico. Es lo que Sohrawardi denomina metahistoria , una historia más allá del mundo, en la que devienen los sucesos de la profecía:

«La historia no se trata de sucesos reales que escapan a lo que llamamos historia real. Puede haber una epopeya cuyo discurso se mantenga en esta historia y puede haber una epopeya cuyo discurso sea la reconquista de la metahistoria, y éste es el discurso místico, la epopeya del gnóstico, del exiliado que, venido a un mundo extranjero, vuelve a su casa, a su mundo. Entre las dos se sitúa la epopeya heroica, cuyo discurso profiere las gestas realizadas por héroes cuya dimensión es otra de la de los personajes de la crónica, porque su persona y su gesta se mueven ya en la dimensión del octavo clima. Y es precisamente esta dimensión la que permitirá a la epopeya heroica acabar en epopeya mística, es decir, encontrar su desenlace en Oriente».8

El universo está ordenado teleológicamente hacia una cima: el Uno. En el proceso de taw $\hat{\imath} l$, de ascenso, se suceden las manifestaciones ontológicas jerarquizadas, ya sea referidas

5 Esta bipartición del Mundo Imaginal en Oriente y Occidente no implica la existencia de un sólo Oriente, sino que existen tantos como mundos, en correspondencia con la jerarquización de las sustancias. Así puede hablarse de un Oriente mayor de las inteligencias querubínicas (Jabarut), Oriente menor de los ángeles o almas celestes (Malakut), un Oriente medio del Mundo Imaginal (Hûrqalyâ). Vid al respecto $\mathrm{H}$. Corbin, Op. cit. p. 108.

6 Jambet, C., Op. cit. p. 119.

7 Ibidem p. 159.

8 Corbin, H., Op. cit. p. 169. 
a órganos de concimiento, lugares geográficos o decursos históricos. Las sustancias existentes en los diferentes mundos han de tener una manifestación histórica correspondiente a su grado de ser. La sustancia perteneciente al mundo sensible pertenece a la historia sensible, mientras que las sustancias imaginales poseen un devenir imaginal, metahistórico.

Conocimiento de, conocimiento a través de: éstos son los dos elementos que definen la situación del hombre con respecto al Ser: según lo que conozca, según cómo lo conozca, será -el ser del hombre. Qué conozca y cómo lo conozca definirán su jerarquía ontológica. El acceso del hombre a Dios es un acceso progresivo, por grados, en el que se va produciendo el desvelamiento de lo batin, de lo oculto. Conforme aumenta el conocimiento del Ser, aumenta el nivel ontológico del hombre. Ello implica, debido a la jerarquización de lo real, entendiendo por tal tanto lo material como lo no material, la adecuación del ser a esos grados de las sustancias y, por lo tanto, la necesidad de órganos de conocimiento en consonancia. En este contexto se encuadran el Profeta enviado ( rasul), el que más cercano se halla a la verdad del Uno, los profetas, los amigos de Dios, los gnósticos. El Uno se deposita en cada uno de ellos en diverso grado, cada uno alcanza la Verdad de un modo proporcional a su ser, pues, tal como dice Jambet: «...la subjetividad no es como el cogito cartesiano una sustancia, sino un modo de ser, un acto de ser, suspendido en la jerarquía ontológica de los universos espirituales».9

La depositación del Uno en todos y cada uno de los seres existentes, en todos los hombres, define el conocimiento como una iluminación. El problema de la epistemología mística sohwardiana se manifiesta como un ascenso progresivo hacia la Verdad, lo que se denomina, como venimos repitiendo, taw îl. Este proceso de ascenso posee un carácter doble: por un lado, en la jerarquía de los mundos, tal como la hemos expresado, y, por otro, como un movimiento interno al ser mismo del hombre, en el que éste trasciende la letra de la escritura, el Corán, hasta llegar a lo que en ella se halla oculto. El objetivo final del taw'îl es el tawhid, la profesión de fe unitaria que podría ser expresada del siguiente modo: «no hay más Dios que Dios». Así es como se genera una dialéctica constante entre el Libro y el hombre, de tal manera que la lectura proporciona el grado ontológico, al tiempo que este grado ontológico define la lectura que se va a realizar. El Corán es el Ser mismo, es universal, pero sus lecturas están mediadas por la subjetividad, son un acto singular:

«...el Corán revelado es siempre fruto de una mirada o interpretación singular, existe para y por la intención exegética de un alma singular. Esta es su verdad singular. (...) He aquí porque como a cada uno su Angel, a cada uno su Corán. Por lo tanto, el Corán ya no es un objeto exterior al alma del que lo interpreta sino que es un suceso, una manifestación de esa alma».. ${ }^{10}$

9 Jambet, C., Op. cit. p. 88.

10 Ibidem p. 113. Aquí cabría poner de manifiesto la cercanía existente entre esta hermenéutica coránica con la hermenéutica de la Biblia, también en acto singular de un hombre con su Dios, instituída por el discurso protestante del XVI europeo. 
Jerarquía de mundos, de geografías, de historias, de seres. La filosofía de Sohrawardi y sus seguidores, los ishraqiyun, está centrada en el proceso de acceso al Ser, tanto por vía sustancial como por vía cognitiva. Es el proceso del taw' $̂$ ll, de interpretación y acceso/ascenso hacia lo oculto, de desvelamiento de la realidad del Ser a través de sus diferentes grados. Toda la realidad que se halla por debajo del Uno es, en un mayor o menor grado, simbólica, de ahí la interpretación como una ascensión hacia la verdad oculta e inalcanzable, evasión de la materialidad, katarsis. La subjetividad se halla ante una tarea de cuyo resultado dependerá su propia definición ontológica: la hermenéutica del Texto, el desvelamiento de sus verdades más ocultas. Dicho desvelamiento se constituye en un viaje en el que el hombre ha de recorrer geografías, mundos y devenires históricos cuyo grado de acercamiento al Ser del Uno es inverso a su cercanía al mundo sensible.

Por ello, en el discurso de Sohrawardi, mundos no materiales, Mundos Imaginales, con sus geografías y devenires, alcanzan un grado de realidad que en nada ha de envidiar al mundo que se ofrece a nuestros sentidos. No sólo existe el ser material; es más, el nivel ontológico de éste se manifiesta como el grado infimo de ser con respecto a la Verdad del Uno. 